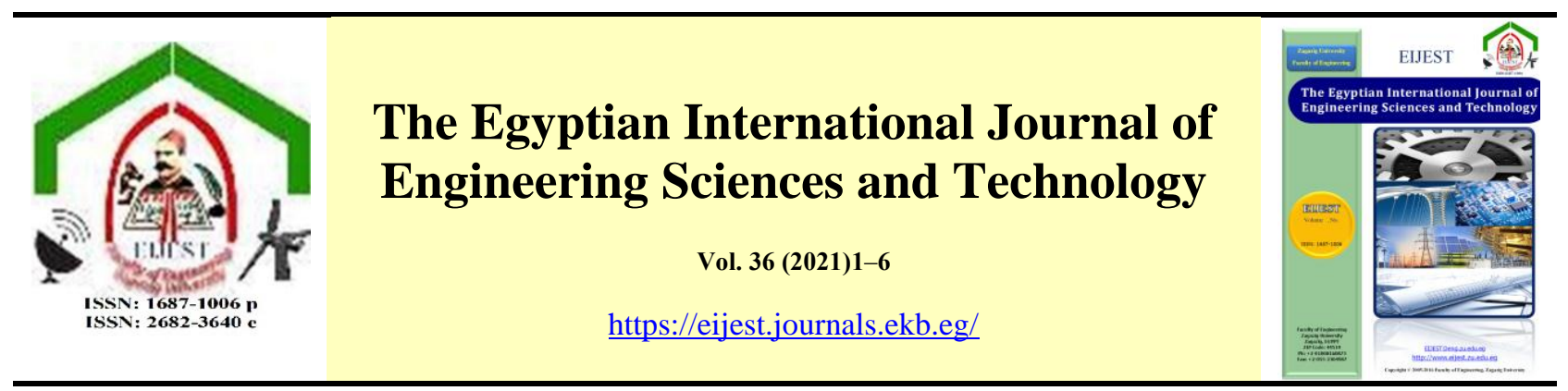

\title{
A Review on Thermal Barrier Coatings
}

\author{
Khaled A. Omran ${ }^{a^{*}}$, Mona Sayed ${ }^{b}$, Mohamed A. El-Meniawi ${ }^{a}$, Hossam E. M. Sallam ${ }^{a}$, \\ Salma M. Naga \\ ${ }^{a}$ Zagazig university, Faculty of Engineering, Materials Engineering Dept, 44519 - Zagazig, Egypt \\ ${ }^{b}$ National Research Center, Ceramics Dept, El-Bohous Str., 12622 - Cairo, Egypt

\section{ARTICLE INFO}

Keywords:

$1^{\text {st }}$ coating,

$2^{\text {nd }}$ TBC materials,

$3^{\text {rd }}$ Processing techniques.

\begin{abstract}
To protect the hot parts of the engine turbines, thermal barrier coatings (TBCs) are exceedingly applied. TBC decreases the temperature of the turbines during operation and hence enhances the engine performance. Recently, researchers have concentrated on developing and processing TBCs for turbine parts. Promoting the thermal barrier coatings will authorize the gas turbines to serve at elevated temperatures. TBCs mostly consists of 2 layers, the bond coat and the topcoat. The topcoat is mainly composed of ceramic materials that possess low thermal conductivity properties, and its main job is to protect the metallic parts from high temperatures.Apparent attempts are being carried out to figure new materials having beneficial fulfillments. To defeat the yttria partially stabilized zirconia (YSZ) troubles, pyrochlore rare-earth zirconate ceramics $\left(\mathrm{A}_{2} \mathrm{~B}_{2} \mathrm{O}_{7}\right)$ have been suggested as most of them are refractory and thermally stable. Hexaaluminates are another suggestion that meets the current requirements of TBCs.The present review summarizes and reviews the novel advance of the materials suitable for Thermal Barrier Coatings, their selection criteria, and their processing techniques.
\end{abstract}

\section{Thermal Barrier Coatings (TBCs):}

Thermal Barrier Coatings (TBCs) are widely applied for producing protection for gas turbine's metallic components such as combustion chamber, blades, and vanes [1,2]. So, the aim of using thermal barrier coatings is to reduce the heat transfer from the high-temperature gas to the metal surface, which leads to enhancement in all of the durability, efficiency, and operating temperature of these engines inside the gas turbines. The thermal barrier coating system consists of a multilayer structure: a bond coat and a topcoat. The topcoat is thermally resistant, whereas the bond coat can be oxidation-resistant $[3,4]$.

Some basic requirements restrict the selection of TBC materials: a) low thermal conductivity, b) no phase transition between room and operating temperatures. c) high melting point, d) chemical inertness, e) matching the thermal expansion of the metallic substrate, f) good adherence to the metallic substrate, and g) low porous microstructure sintering rate [5]. So, it is a must to select the materials used for TBCs depending on these requirements. Accordingly, the most selected material acceptable to these requirements is ceramics due to its excellent properties such as good mechanical properties, low ductility, melting point and thermal expansion, high dimensional stability, and resistance to corrosion and chemical attack, reasonable thermal expansion, and thermal conductivity, etc. [6, 7].

Accordingly, looking for materials with eligible properties to be used for high-temperature thermal barrier coatings is necessary [8]. The main problems

* Corresponding author. Tel.: +02-01011021964

E-mail address: khaled.ahmed4294@gmail.com 
in developing new thermal barrier coating materials are:

- $\quad$ Finding oxide materials, which possess the ability for high thermal resistivity.

- Access oxides that are thermodynamically stable with alumina.

- To produce and stabilize the internal porosity as the reduction in the heat transfer cross-section through the pores leads to an essential decrease in the thermal conductivity from the intrinsic thermal conductivity of the material.

\section{Material for TBC:}

\subsection{Zirconia $\left(\mathrm{ZrO}_{2}\right)$ :}

In the engine industry field, zirconia is found to be good to use in many applications such as thermal insulative coating [TBC] or as (Environmental Barrier Coating [EBC]). Accordingly, zirconia-based coatings are considered a practical choice for providing combined protection and increasing the lifetime of the metallic components [9].

Zirconia is used for coating due to its characteristics, such as the extremely low thermal conductivity, which almost lower than these for the metallic components as it's approximately about $(2 \mathrm{~W} / \mathrm{m} . \mathrm{K})$. It is widely available and easy to use for deposition as coatings through various thermal processes. The components with a high lifetime could be produced from these high insulative ceramics with a thickness of approximately $2 \mathrm{~mm}$ or less. The lifetime could be enhanced for several orders of magnitude. Although these coatings provide promising solutions for the industry of TBC, many obstacles hinder its spread. One of these barriers is its poor adhesion to the metal substrate, which causes a limiting in the lifetime and durability of the coating [9].

Finally, the most effective way for producing zirconia coating is through thermal processes such as the thermal spray process, which is considered the most effective way with less engineering issues. Such coatings are characterized by high thermal insulating, high wear, and oxidation and corrosion resistance [9].

\subsection{Zirconia-Toughened-Alumina (ZTA):}

Although $\mathrm{Al}_{2} \mathrm{O}_{3}$ has favorable properties, it did not prove itself as the proper material for TBC application. Alumina has a low thermal expansion coefficient and relatively high thermal conductivity in comparison to YSZ, which is considered as alumina's most drawbacks [10]. So, alumina alone isn't suitable to use as a thermal barrier coating
(TBC). $\mathrm{ZrO}_{2}$, which has low thermal conductivity and high toughness, was combined with alumina, which has a high hardness to form zirconiatoughened-alumina (ZTA) composites. ZTA possesses promising properties that candidates can use as functionally graded TBC material for so many applications [11].

(ZTA) Composites consist of an alumina-rich composition where the matrix microstructure is modified by zirconia as a second phase. The even dispersion of zirconia in the alumina matrix produces a ceramic body with superior strength and toughness, improved chemical stability [12], an appropriate thermal conductivity of about $20 \mathrm{~W} / \mathrm{mK}$, and a composite body serving at an elevated temperature of about $1650-1700^{\circ} \mathrm{C}[13,14]$. At the same time, alumina does not lose its high hardness and stability by preventing crack propagation and abnormal grain growth [12]. It was found that the addition of small $\mathrm{ZrO}_{2}$ grains to the alumina matrix reduced the aging process $[15,16]$. Mechanical strength, elasticity, hardness, and wear resistance improvement of the ZTA composites are accomplished through the transformation toughening phenomenon, which is responsible for transforming (t-zirconia) into the (mzirconia) under loading. The microstructure of the alumina/zirconia composite has a complicated effect on toughening, such as shape, volume fraction, size, location, and size distribution of $\mathrm{ZrO}_{2}$ [17].

\subsection{Rare Earth Zirconates:}

In the literature, various approaches have been found to overcome the YSZ problems. The tendency for phase transformation at elevated temperatures has been addressed by changing the oxides used for stabilizing the $\mathrm{ZrO}_{2}$. The $\mathrm{A}_{2} \mathrm{~B}_{2} \mathrm{O}_{7}$ - type rare-earth zirconate ceramics, such as $\mathrm{Sc}_{2} \mathrm{Zr}_{2} \mathrm{O}_{7}, \mathrm{In}_{2} \mathrm{Zr}_{2} \mathrm{O}_{7}$, $\mathrm{La}_{2} \mathrm{Zr}_{2} \mathrm{O}_{7}, \mathrm{Nd}_{2} \mathrm{Zr}_{2} \mathrm{O}_{7}, \mathrm{Sm}_{2} \mathrm{Zr}_{2} \mathrm{O}_{7}$, and $\mathrm{Gd}_{2} \mathrm{Zr}_{2} \mathrm{O}_{7}$, have obtained massive interest from researchers as potential TBC materials in the future. [18, 19]. They crystallize into an ordered pyrochlore structure over a range of compositions. Small amounts of impurities, especially $\mathrm{SiO}_{2}$, are added to decrease the sintering of YSZ coatings [20]. $\mathrm{CeO}_{2}$ is an alternative stabilizer. It has good corrosion resistance, and at high temperatures, the phase stability is excellent [21]. $\mathrm{CeO}_{2}$-stabilized $\mathrm{ZrO}_{2}$ (CSZ) has a lower thermal conductivity than YSZ. Furthermore, spalling resistance has been reported during thermal cycling [22]. The $\mathrm{ZrO}_{2}-\mathrm{CeO}_{2}$ system has a narrow range of compositions (> $15 \mathrm{wt} \%$ and $<19 \mathrm{wt} \%)$. Within the tetragonal field at $1400-1500^{\circ} \mathrm{C}$, these compositions are non-transformable and intrinsically phase-stable. 
[23]. At elevated temperatures, disordered fluorite is the stable phase [23, 24]. It is also the stable phase outside the composition range [23]. Cao et al. [25] showed that lanthanum zirconate (LZ) coatings have good heat stability. And they claimed that enhancement of the thermal cycling life of LZ coatings could be achieved through: (1) doping elements into $\mathrm{LZ}$ to improve the thermal expansion coefficient, (2) increasing the $\mathrm{L}_{2} \mathrm{O}_{3}$ content by about $5 \%$, and (3) using graded coatings with YSZ.

The effect of adding $\mathrm{Ta}_{2} \mathrm{O}_{5}$ and $\mathrm{Nb}_{2} \mathrm{O}_{5}$ to bulk $\mathrm{Y}_{2} \mathrm{O}_{3}$-stabilized tetragonal $\mathrm{ZrO}_{2}$ has been studied by many researchers [26, 27]. When immersed in the $\mathrm{ZrO}_{2}$ lattice, pentavalent oxides, unlike trivalent oxides, are positively charged. In the zirconia lattice, they exist as substitutional defects, eliminating the vacancies of oxygen caused by yttria doping. Thus, Because of the mismatch in ionic radius and atomic interaction, it is assumed that defects produced by pentoxides will lower thermal conductivity by dispersing phonons. [28, 29]. Lowering thermal conductivity, enhancing mechanical characteristics, and raising the temperature at which $\mathrm{t}-\mathrm{ZrO} 2$ transforms to $\mathrm{m}-\mathrm{ZrO} 2$ could be obtained through Doping YSZ with pentavalent oxides. [30]. The alloying influence on the tetragonality of t-zirconia is the reason for the increase in phase transition temperature. [31]. These systems, on the other hand, have a high tetragonality, showing that pentavalent oxides cause greater tetragonal deformation of the cubic lattice.

\section{Hexaaluminates:}

Lanthanide hexaaluminate has been employed for TBCs applications as a result of its low thermal conductivity, high thermal expansion and melting point, structure stability up to $1800^{\circ} \mathrm{C}$, and excellent long-term sintering resistance. The nominal composition is ( $\mathrm{La}, \mathrm{Nd}$ ) $\mathrm{MAl}_{11} \mathrm{O}_{19}$, where $\mathrm{M}=\mathrm{Mg}$, $\mathrm{Mn}$ to $\mathrm{Zn}, \mathrm{Cr}$, or $\mathrm{Sm}$ [32]. The most exciting composition is $\mathrm{LaMgAl}_{11} \mathrm{O}_{19}[33,34]$. Lanthanate species doesn't have a vital role in The thermal expansion of $\mathrm{LnMgAl}_{11} \mathrm{O}_{19}(\mathrm{Ln}=\mathrm{La}, \mathrm{Gd}, \mathrm{Sm}$ or $\mathrm{Yb})$, and co-doping can be used for decreasing its thermal conductivity, which is the same as the behavior of zirconate pyrochlores $[35,36]$. High fracture toughness and low young's modulus is the reason for long thermal cyclic life of these coatings. The randomness of lanthanum hexaaluminate platelets has a great effect on the coating's properties, which reduces the thermal conductivity and produces a well-balanced micro-porosity of the product. The morphology of these platelets is dependent on the sampling process as well as its composition [37]. The major drawbacks of these materials are:

- The recrystallization phenomenon during plasma spray deposition.

- The temperature requirements during calcination of sol-gel or the dipping technique.

- The volatilization of magnesium during the EBPVD process [38].

The segmentation crack networks formed by plasma-sprayed coatings are remarkable, which are thought to be the result of a stress release mechanism, and also improves the coatings' strain tolerance. A superior lifetime was found during a thermal-gradient burner rig test of a hexaaluminate multilayers TBC system with an intermediate YSZ layer [39].

\section{Processing techniques for TBCs:}

Figure.1 illustrated the different methods applied for the preparation of the TBC layers [40]. Despite the abundant techniques employed for the deposition of the TBCs, the air plasma spray (APS) and electron beam-physical vapor deposition (EB-PVD) remains the most extensively used techniques for the deposition of YSZ coating, which has 7-8 wt $\% \mathrm{Y}_{2} \mathrm{O}_{3}$ [41, 42].

The following illustrated some techniques used for the deposition of the ceramic coatings on the metallic substrate.

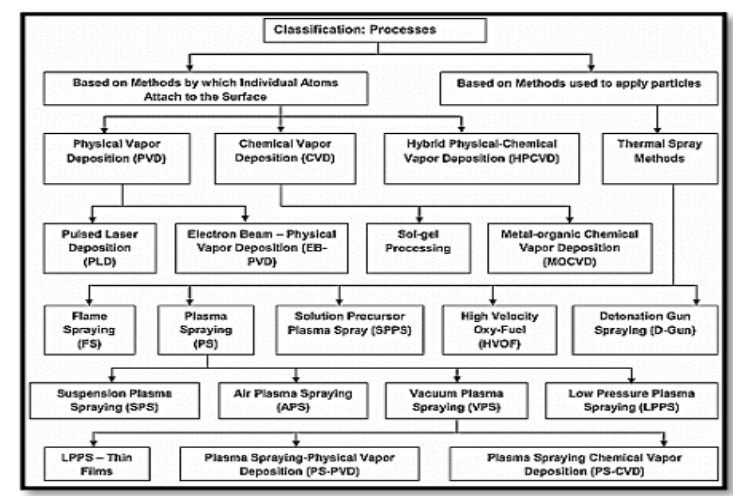

Fig.1. classification of coating processing methods [40].

\subsection{Air plasma-sprayed (APS) process:}

In this technique, the used TBC powder is inserted into an elevated-temperature plasma plume, where the powder was fused and expedited toward the substrate. The molten droplets are diffused to form splats, which are quickly dampened down. It is possible to deposit several consecutive splats by a 
single pass, and the thickness of the coating can be boosted by repeating the passes. The ideal crosssection of plasma sprayed coating is represented by splats layers having interlamellar pores, cracks, and spherical pores [43]. The parameters that governed the coating microstructure rely on the operation status like, 1) the spray parameters (torch flow, the speed of torch traverse, carrier and plasma gas flow rate, and standoff distance and 2) feedstock materials (velocity, temperature, and grain size). The shocking particle impact angle affects the morphologies of splats. [43]. Because of the oxidation of the bond coat, a Thermally-Grown Oxide (TGO) coat is formed amidst the top coating and the bond-coating during service at elevated temperatures. The TGO coat is negatively affected the lifetime of the thermal barrier coating. Functionally graded TBC coating was developed in order to decrease the big residual stresses accompanied by the TGO coat formation [44].

\subsection{Electron Beam-Physical Vapor Deposition (EB- $P V D)$ :}

EB-PVD is one of the most common techniques for TBC top coatings. The coating procedure is carried out by converting the coating material into vapor through its heating by an electron beam. Then the evaporated material is condensed on the metallic substrate to form crystal nuclei, which later grow to develop the particular sideways $\mathrm{ZrO} 2$ pillar microstructure [43]. The deficiency of this technique is the formation of a thermally growing oxide layer (TGO layer) on the bond coat. The formation of the TGO layer is destructive for the TBC execution as its presence enhanced the residual stresses, which boosts the brittleness of the topcoat and decreasing the adhesion between the bond coat and the topcoat [45].

\subsection{Electrostatic Spray-Assisted Vapor Deposition method (ESAVD):}

The electrostatic spray-assisted vapor deposition (ESAVD) method is a modern low expensive procedure for YSZ coatings deposition. This method is based on splattering $\mathrm{Zr}$ and $\mathrm{Y}$ alkoxides small drops within an electric field. Such a procedure will evaporate the droplets and led to a chemical reaction between the precursors in the vapor phase very close to the hot substrate, where they will precipitate [46].

\subsection{Solution-Precursor Plasma Spray (SPPS) process:}

This technique is based on injecting the starting materials in an aqueous form into the plasma jet. It will subject the starting materials droplets to physical and chemical reactions before coating the substrate. TBCs deposited by the (SPPS) technique display outstanding durability comparing to TBCs applied by the APS and (EB-PVD) processes [47]. They show an average thermal cycling life of 820 cycles comparing to 40 thermal cycles for the conventional air plasma-sprayed coatings [48].

\subsection{Sol-gel process:}

A novel sol-gel method was achieved to prepare and precipitate the TBCs [49]. It is possible to form and precipitate either thin or thick non-directed TBC coating by dipping or spraying for the prepared solgel TBC coat or combining both techniques. It was noticed that the TBCs prepared by such methods started to degrade and to form a network of systematic cracks either during the sintering process of the sol-gel or during the 1st run of oxidation. After that, and because of the compressive heating runs, expansion and cohesion of the cracks occur, which encourage the separation of the TBC layers and, at last, the complete fragmentation of the TBC. There are two ways to overcome such a problem: 1) improving the oxidation process of the precipitated sol-gel, or 2) stabilization of the crack network by stuffing the crack channels by an additional dip or spray-coating [50].

\section{Conclusions}

TBC systems are used for protecting gas turbines and other engine components to serve in hightemperature environments and improve these engines' durability and efficiency. To achieve its purpose, TBCs required the design and development of advanced ceramic materials such as yttria partially stabilized zirconia (YSZ), pyrochlore rare-earth zirconates $\left(\mathrm{A}_{2} \mathrm{~B}_{2} \mathrm{O}_{7}\right)$, and Hexaaluminates. There are so many coating processing techniques used for the deposition of the ceramic coatings on the metallic substrate that allow good bonding between the metal substrate and the ceramic layers. This study comprehensively reviews the current techniques used for ceramic layer deposition on the surface of the metallic substrate. 


\section{References}

[1] B. Gleeson, "Thermal barrier coatings for aeroengine applications," Journal of propulsion and power, vol. 22, pp. 375-383, 2006.

[2] R. Vassen, A. Stuke, and D. Stöver, "Recent developments in the field of thermal barrier coatings," Journal of thermal spray technology, vol. 18, pp. 181-186, 2009.

[3] D. R. Clarke, M. Oechsner, and N. P. Padture, "Thermalbarrier coatings for more efficient gas-turbine engines," MRS bulletin, vol. 37, pp. 891-898, 2012.

[4] C. U. Hardwicke and Y.-C. Lau, "Advances in thermal spray coatings for gas turbines and energy generation: a review," Journal of Thermal Spray Technology, vol. 22, pp. 564-576, 2013.

[5] P. M. Ajayan, L. S. Schadler, and P. V. Braun, Nanocomposite science and technology: John Wiley \& Sons, 2006.

[6] P. Boch and J.-C. Niepce, Ceramic Materials: Processes, Properties, and Applications vol. 98: John Wiley \& Sons, 2010.

[7] M. Bengisu, Engineering ceramics: Springer Science \& Business Media, 2013.

[8] D. R. Clarke, "Materials selection guidelines for low thermal conductivity thermal barrier coatings," Surface and Coatings Technology, vol. 163, pp. 67-74, 2003.

[9] J. J. Swab, "Role of oxide additives in stabilizing zirconia for coating applications," ARMY RESEARCH LAB ABERDEEN PROVING GROUND MD2001.

[10] W. Ma and H. Dong, "Ceramic thermal barrier coating materials," in Thermal barrier coatings, ed: Elsevier, 2011, pp. 25-52.

[11] W. Y. Lee, D. P. Stinton, C. C. Berndt, F. Erdogan, Y. D. Lee, and Z. Mutasim, "Concept of functionally graded materials for advanced thermal barrier coating applications," Journal of the American Ceramic Society, vol. 79, pp. 3003$3012,1996$.

[12] P. Palmero, F. Kern, M. Lombardi, and R. Gadow, "Role of immiscible and miscible second phases on the sintering kinetics and microstructural development of nano-crystalline $\alpha$-Al2O3-based materials," Ceramics International, vol. 37, pp. 3547-3556, 2011.

[13] S. K. Saini, A. K. Dubey, B. N. Upadhyay, and A. Choubey, "Study of hole characteristics in Laser Trepan Drilling of ZTA," Optics \& Laser Technology, vol. 103, pp. 330-339, 2018/07/01/2018

[14] N. Chuankrerkkul, K. Somton, T. Wonglom, K. Dateraksa, and P. Laoratanakul, "Physical and Mechanical Properties of Zirconia Toughened Alumina (ZTA) Composites Fabricated by Powder Injection Moulding," Chiang Mai Journal of Science, vol. 43, pp. 375-380, 01/01 2016.

[15] M. Guazzato, M. Albakry, S. P. Ringer, and M. V. Swain, "Strength, fracture toughness and microstructure of a selection of all-ceramic materials. Part I. Pressable and alumina glass-infiltrated ceramics," Dental materials, vol. 20, pp. 441-448, 2004.

[16] D. Gutknecht, J. Chevalier, V. Garnier, and G. Fantozzi, "Key role of processing to avoid low temperature ageing in alumina zirconia composites for orthopaedic application," Journal of the European Ceramic Society, vol. 27, pp. 15471552,2007

[17] https://www.insaco.com/materials/aluminum-oxides/aluminazta, ed

[18] J. Wu, X. Wei, N. P. Padture, P. G. Klemens, M. Gell, E. García, et al., "Low- thermal- conductivity rare- earth zirconates for potential thermal- barrier- coating applications," Journal of the American Ceramic Society, vol. 85, pp. 3031-3035, 2002
[19] Q. Xu, W. Pan, J. Wang, C. Wan, L. Qi, H. Miao, et al., "Rare- earth zirconate ceramics with fluorite structure for thermal barrier coatings," Journal of the American Ceramic Society, vol. 89, pp. 340-342, 2006.

[20] X. Q. Cao, R. Vassen, and D. Stöver, "Ceramic materials for thermal barrier coatings," Journal of the European Ceramic Society, vol. 24, pp. 1-10, 2004.

[21] B. A. Nagaraj, A. F. Maricdcchi, D. J. Wortman, J. S. Patton, and R. L. Clarke, "Hot Corrosion Resistance of Thermal Barrier Coatings," 1992.

[22] C. H. Lee, H. K. Kim, H. S. Choi, and H. S. Ahn, "Phase transformation and bond coat oxidation behavior of plasmasprayed zirconia thermal barrier coating," Surface and Coatings Technology, vol. 124, pp. 1-12, 2000.

[23] E. Y. Lee, Y. h. Sohn, S. K. Jha, J. W. Holmes, and R. D. Sisson, "Phase Transformations of Plasma- Sprayed Zirconia-Ceria Thermal Barrier Coatings," Journal of the American Ceramic Society, vol. 85, pp. 2065-2071, 2002.

[24] J. R. Brandon and R. Taylor, "Phase stability of zirconiabased thermal barrier coatings part II. Zirconia-ceria alloys," Surface and coatings technology, vol. 46, pp. 91-101, 1991.

[25] X. Q. Cao, R. Vassen, W. Jungen, S. Schwartz, F. Tietz, and D. Stöver, "Thermal stability of lanthanum zirconate plasma- sprayed coating," Journal of the American Ceramic Society, vol. 84, pp. 2086-2090, 2001.

[26] D. S. Almeida, C. R. M. Silva, M. C. A. Nono, and C. A. A. Cairo, "Thermal conductivity investigation of zirconia codoped with yttria and niobia EB-PVD TBCs," Materials Science and Engineering: A, vol. 443, pp. 60-65, 2007.

[27] X. Song, M. Xie, R. Mu, F. Zhou, G. Jia, and S. An, "Influence of the partial substitution of $\mathrm{Y} 2 \mathrm{O} 3$ with $\mathrm{Ln} 2 \mathrm{O} 3$ $(\mathrm{Ln}=\mathrm{Nd}, \mathrm{Sm}, \mathrm{Gd})$ on the phase structure and thermophysical properties of $\mathrm{ZrO} 2-\mathrm{Nb} 2 \mathrm{O} 5-\mathrm{Y} 2 \mathrm{O} 3$ ceramics," Acta Materialia, vol. 59, pp. 3895-3902, 2011.

[28] F. M. Pitek and C. G. Levi, "Opportunities for TBCs in the ZrO2-YO1. 5-TaO2. 5 system," Surface and Coatings Technology, vol. 201, pp. 6044-6050, 2007.

[29] M. R. Winter and D. R. Clarke, "Thermal conductivity of yttria-stabilized zirconia-hafnia solid solutions," Acta materialia, vol. 54, pp. 5051-5059, 2006.

[30] S. Raghavan, H. Wang, W. D. Porter, R. B. Dinwiddie, and M. J. Mayo, "Thermal properties of zirconia co-doped with trivalent and pentavalent oxides," Acta materialia, vol. 49, pp. 169-179, 2001.

[31] K. A. Khor and J. Yang, "Transformability of t-ZrO 2 and lattice parameters in plasma sprayed rare-earth oxides stabilized zirconia coatings," Scripta materialia, vol. 37, pp. 1279-1286, 1997.

[32] "R. Gadow , G.W. Schäfer : Patent 99-EP982 9942630, Wo ( 1999 ).".

[33] C. Friedrich, R. Gadow, and T. Schirmer, "Lanthanum hexaaluminate - a new material for atmospheric plasma spraying of advanced thermal barrier coatings," Journal of thermal spray technology, vol. 10, pp. 592-598, 2001.

[34] R. Gadow and M. Lischka, "Lanthanum hexaaluminatenovel thermal barrier coatings for gas turbine applicationsmaterials and process development," Surface and Coatings Technology, vol. 151, pp. 392-399, 2002.

[35] N. P. Bansal and D. Zhu, "Thermal properties of oxides with magnetoplumbite structure for advanced thermal barrier coatings," Surface and Coatings Technology, vol. 202, pp. 2698-2703, 2008.

[36] J. Zhang, X. Zhong, Y. Cheng, Y. Wang, Z. Xu, X. Chen, et al., "Thermal-shock resistance of LnMgAl11O19 ( $\mathrm{Ln}=\mathrm{La}$, $\mathrm{Nd}, \mathrm{Sm}, \mathrm{Gd})$ with magnetoplumbite structure," Journal of alloys and compounds, vol. 482, pp. 376-381, 2009.

[37] P. Y. Jia, M. Yu, and J. Lin, "Sol-gel deposition and luminescent properties of $\mathrm{LaMgAl11019}$ : $\mathrm{Ce} 3+/ \mathrm{Tb} 3+$ 
phosphor films," Journal of Solid State Chemistry, vol. 178, pp. 2734-2740, 2005.

[38] H. Inoue, K. Sekizawa, K. Eguchi, and H. Arai, "Thick-film coating of hexaaluminate catalyst on ceramic substrates for high-temperature combustion," Catalysis today, vol. 47, pp. 181-190, 1999.

[39] B. R. Lawn, N. P. Padture, H. Cait, and F. Guiberteau, "Making ceramics" ductile"," Science, vol. 263, pp. 11141116, 1994.

[40] V. Kumar and B. Kandasubramanian, "Processing and design methodologies for advanced and novel thermal barrier coatings for engineering applications," Particuology, vol. 27, pp. 1-28, 2016.

[41] A. M. Limarga and D. R. Clarke, "Characterization of Electron Beam Physical Vapor- Deposited Thermal Barrier Coatings Using Diffuse Optical Reflectance," International Journal of Applied Ceramic Technology, vol. 6, pp. 400-409, 2009.

[42] R. Vaßen, M. O. Jarligo, T. Steinke, D. E. Mack, and D. Stöver, "Overview on advanced thermal barrier coatings," Surface and Coatings Technology, vol. 205, pp. 938-942, 2010.

[43] A. Kulkarni, A. Vaidya, A. Goland, S. Sampath, and H. Herman, "Processing effects on porosity-property correlations in plasma sprayed yttria-stabilized zirconia coatings," Materials Science and Engineering: A, vol. 359, pp. 100-111, 2003.

[44] H. B. Guo, S. Kuroda, and H. Murakami, "Segmented thermal barrier coatings produced by atmospheric plasma spraying hollow powders," Thin Solid Films, vol. 506, pp. 136-139, 2006.

[45] D. Zhang, S. Gong, H. Xu, and Z. Wu, "Effect of bond coat surface roughness on the thermal cyclic behavior of thermal barrier coatings," Surface and Coatings Technology, vol. 201, pp. 649-653, 2006.

[46] J. D. Vyas and K. L. Choy, "Structural characterisation of thermal barrier coatings deposited using electrostatic spray assisted vapour deposition method," Materials Science and Engineering: A, vol. 277, pp. 206-212, 2000.

[47] M. Gell, L. Xie, X. Ma, E. H. Jordan, and N. P. Padture, "Highly durable thermal barrier coatings made by the solution precursor plasma spray process," Surface and Coatings Technology, vol. 177, pp. 97-102, 2004.

[48] A. Jadhav, N. P. Padture, F. Wu, E. H. Jordan, and M. Gell, "Thick ceramic thermal barrier coatings with high durability deposited using solution-precursor plasma spray," Materials Science and Engineering: A, vol. 405, pp. 313-320, 2005.

[49] J. Sniezewski, Y. LeMaoult, P. Lours, L. Pin, V. M. Bekale, D. Monceau, et al., "Sol-gel thermal barrier coatings: Optimization of the manufacturing route and durability under cyclic oxidation," Surface and Coatings Technology, vol. 205, pp. 1256-1261, 2010.

[50] L. Pin, F. Ansart, J.-P. Bonino, Y. Le Maoult, V. Vidal, and P. Lours, "Processing, repairing and cyclic oxidation behaviour of sol-gel thermal barrier coatings," Surface and Coatings Technology, vol. 206, pp. 1609-1614, 2011. 